\title{
Radium and Barium Removal through Blending Hydraulic Fracturing Fluids with Acid Mine Drainage
}

\author{
Andrew J. Kondash, ${ }^{\dagger}$ Nathaniel R. Warner, ${ }^{\dagger, \S}$ Ori Lahav, ${ }^{\ddagger}$ and Avner Vengosh ${ }^{*}{ }^{\dagger}$ \\ ${ }^{\dagger}$ Division of Earth and Ocean Sciences, Nicholas School of the Environment, Duke University, Durham, North Carolina 27708, \\ United States \\ ${ }^{\ddagger}$ Civil and Environmental Engineering, Technion, Haifa 32000, Israel
}

Supporting Information

ABSTRACT: Wastewaters generated during hydraulic fracturing of the Marcellus Shale typically contain high concentrations of salts, naturally occurring radioactive material (NORM), and metals, such as barium, that pose environmental and public health risks upon inadequate treatment and disposal. In addition, fresh water scarcity in dry regions or during periods of drought could limit shale gas development. This paper explores the possibility of using alternative water sources and their impact on NORM levels through blending acid mine drainage (AMD) effluent with recycled hydraulic fracturing flowback fluids (HFFFs). We conducted a series of laboratory experiments in which the chemistry and NORM of different mix proportions of AMD and HFFF were examined after reacting for $48 \mathrm{~h}$. The experimental data combined with geochemical modeling and X-ray diffraction analysis suggest that several ions, including sulfate, iron, barium, strontium, and a large portion of radium (60-

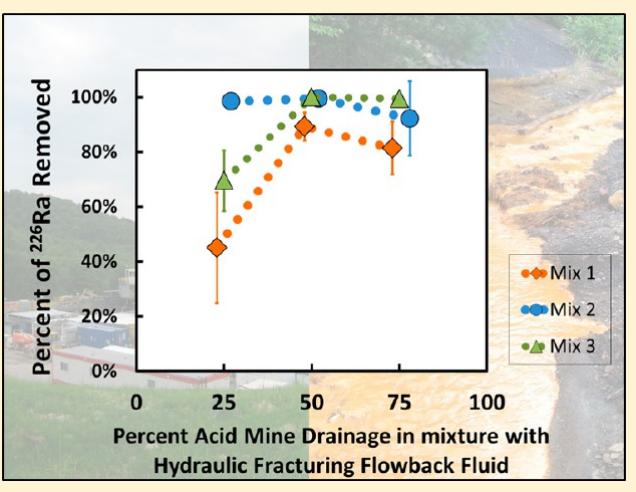
$100 \%$ ), precipitated into newly formed solids composed mainly of Sr barite within the first $\sim 10 \mathrm{~h}$ of mixing. The results imply that blending AMD and HFFF could be an effective management practice for both remediation of the high NORM in the Marcellus HFFF wastewater and beneficial utilization of AMD that is currently contaminating waterways in northeastern U.S.A.

\section{INTRODUCTION}

The possible environmental risks associated with the management and disposal of hydraulic fracturing flowback fluid (HFFF) wastewater have generated public debate about the safety of unconventional shale gas development and hydraulic fracturing. In the northeastern U.S.A., Marcellus HFFF is composed of highly saline water with elevated levels of elements, such as barium and strontium, along with high levels of naturally occurring radioactive materials (NORMs) in the form of radium isotopes. ${ }^{1-6}$ The high levels of salinity and radioactivity characterize both the waters that flow to the surface following hydraulic fracturing (i.e., "flowback water") and during gas production ("produced water"). In areas where this wastewater is disposed to the environment, the elevated salinity has been shown to contaminate streams ${ }^{7}$ and was also associated with accumulation of radium isotopes in stream sediments at disposal sites in Pennsylvania. ${ }^{1}$

In addition to the potential environmental effects of HFFF wastewaters, the water volumes necessary for the hydraulic fracturing process can add an additional constraint to the development of shale gas. Water consumption for the hydraulic fracturing of shale formations varies from 8000 to $50000 \mathrm{~m}^{3}$ (from 2 to 13 million gallons) per unconventional well. ${ }^{6,8-12}$ The overall water footprint of unconventional shale gas development per unit of energy produced is lower relative to conventional oil and gas wells ${ }^{12}$ and other energy production, such as coal combustion, but in some areas, large-scale development of shale gas can cause depletion and overexploitation of the local water resources. ${ }^{8}$ The total water use for hydraulic fracturing in the Marcellus Formation in Pennsylvania was between 42 and $66 \times 10^{6} \mathrm{~m}^{3}$ in 2011 , ${ }^{12}$ of which the majority was freshwater, although wastewater recycling has substantially increased in the past 2 years. ${ }^{13}$ To mitigate water stress in areas during times of water scarcity, alternative or marginal water sources should be considered as substitutes for the freshwater component of hydraulic fracturing applications. In the northeastern U.S.A., a potential alternative water source is acid mine drainage (AMD; Figure 1). ${ }^{5,14} \mathrm{~A}$ volume of approximately $2.3 \times 10^{9} \mathrm{~m}^{3}$ of AMD is annually discharged to waterways in Pennsylvania, causing the degradation of over $20000 \mathrm{~km}$ of streams and rivers (Figure 1). ${ }^{15-17}$ At the same time, oil and gas operations in the Marcellus Formation generate from $3.1 \times 10^{6}$ to $3.8 \times 10^{6} \mathrm{~m}^{3}$ of wastewater per year, a portion of which is currently treated at centralized waste treatment facilities and discharged to the local rivers. ${ }^{1,7,12,13}$

The use of AMD as an alternative water source for hydraulic fracturing (Figure 1) could both alleviate water stress on limited water resources as well as decrease the load of salts and

Received: August 29, 2013

Revised: December 14, 2013

Accepted: December 16, 2013 


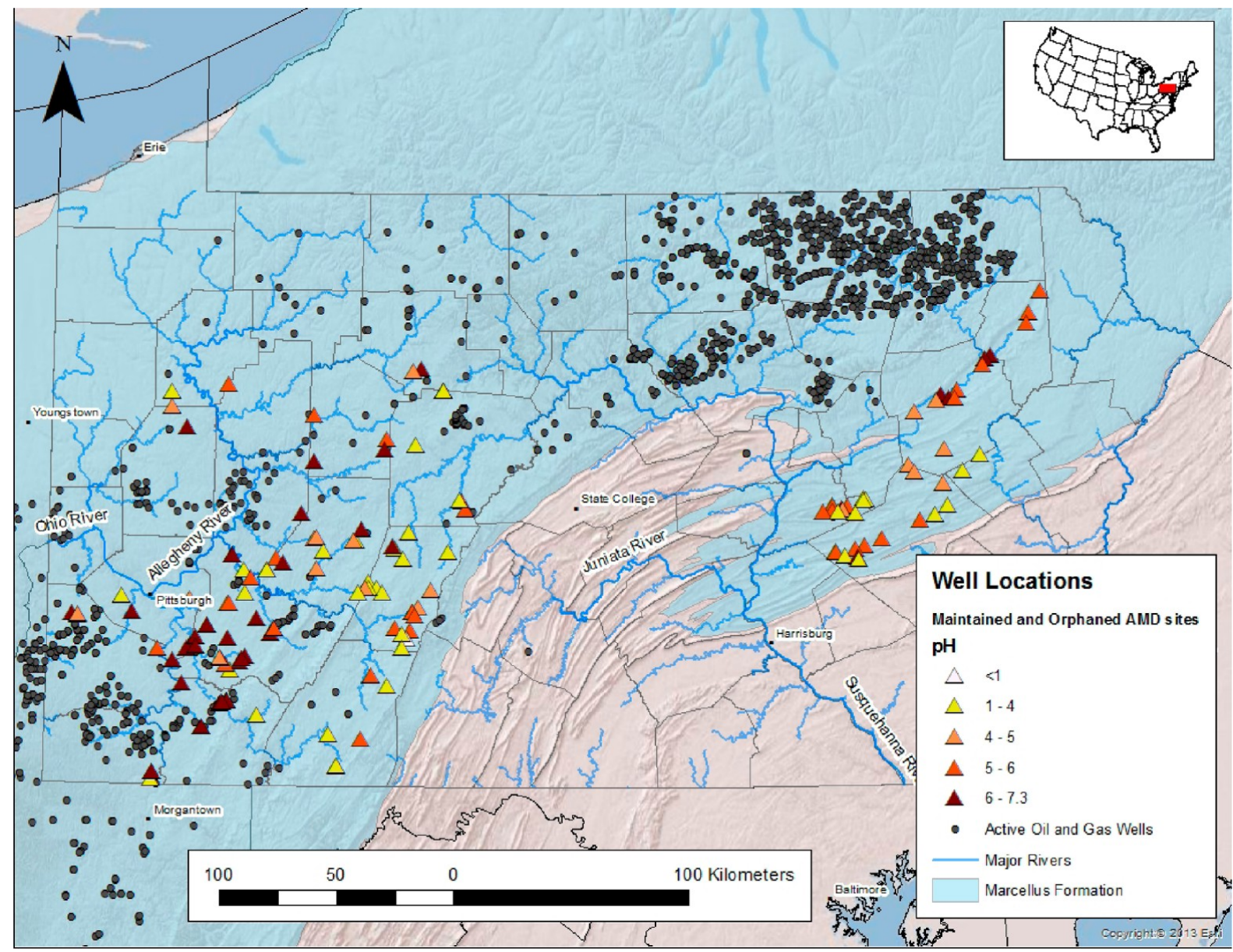

Figure 1. Map of AMD sites (triangles; color-coded based on $\mathrm{pH}$ ) and active shale gas wells (gray circles) of the Marcellus Formation in Pennsylvania (light blue polygon). Note the proximity of AMD sites to shale gas development, particularly in southwestern Pennsylvania. ${ }^{50}$

trace metals requiring treatment from both $\mathrm{AMD}$ and HFFF. $^{18,19}$ However, the ability to use AMD for hydraulic fracturing depends upon the chemical reactivity and precipitation of minerals upon mixing of HFFF and AMD ${ }^{14}$ The blending of HFFFs that are typically enriched in $\mathrm{Ca}, \mathrm{Sr}, \mathrm{Ba}$, and $\mathrm{Ra}$ with sulfate-rich AMD could form solid precipitates that would remove some of the metals and NORMs but could also result in scaling and clogging during the hydraulic fracturing process. $^{15,20,21}$

The objectives of this study are to evaluate the impact of blending typical Marcellus HFFF with AMD from Pennsylvania and systematically monitor the resulting chemical variations. We conducted a series of laboratory mixing experiments with different types and proportions of AMD and HFFF and then measured the chemical and NORM variations that resulted in the different mix products. We used both typical AMD (e.g., low $\mathrm{pH}$ and high iron) $)^{16,20,22}$ and modified AMD (acidity buffered by the addition of lime that generated higher $\mathrm{pH}$ effluents with low iron and high calcium contents). ${ }^{16,17,20}$ By monitoring the chemical variations of the residual solutions and both measuring and modeling the resulting co-precipitated mineral phases, we provide a systematic evaluation of the modifications to the quality of the effluents and the composition of solid residues that are generated from mixing AMD and HFFF.

\section{METHODS}

Sample Collection and Blending Experiments. HFFFs from three Marcellus drilling sites in western PA and two different lime-treated AMD samples were provided by Consol Energy, Inc. The AMD sites are co-located with the Marcellus wells and are being considered for field-scale use as HFFF. A synthetic AMD sample that represents typical iron-rich and low-pH AMD effluent ${ }^{22}$ (see Table S1 of the Supporting Information) was also evaluated in the study. AMD and HFFF samples were analyzed for major elemental chemistry $\left(\mathrm{SO}_{4}, \mathrm{Cl}\right.$, $\mathrm{HCO}_{3}, \mathrm{Ca}, \mathrm{Mg}, \mathrm{Sr}, \mathrm{Na}$, and $\mathrm{Ba}$ ) and radium isotopes $\left({ }^{226} \mathrm{Ra}\right)$. Six treated AMD-HFFF sets and six synthetic AMD-HFFF sets were mixed using 25,50 , and $75 \% \mathrm{AMD}$ in the mixtures for a total volume of $50 \mathrm{~mL}$ and were shaken for $48 \mathrm{~h}$. An aliquot of mixture was filtered and subsequently analyzed. The actual measured concentrations from each of the blends were subtracted from expected concentrations and calculated assuming theoretical conservative mixing (i.e., the combined concentrations of the AMD-HFFF solution represent the relative contributions of $\mathrm{AMD}$ and $\mathrm{HFFF}$ ). For each solute, the relative fraction that was removed in comparison to the expected concentration based on conservative mixing was calculated and expressed as percent removal. The difference (expected minus measured) provided an estimate of the nature and magnitude of the precipitates that formed as a result of the mixing, which was confirmed through further testing. 


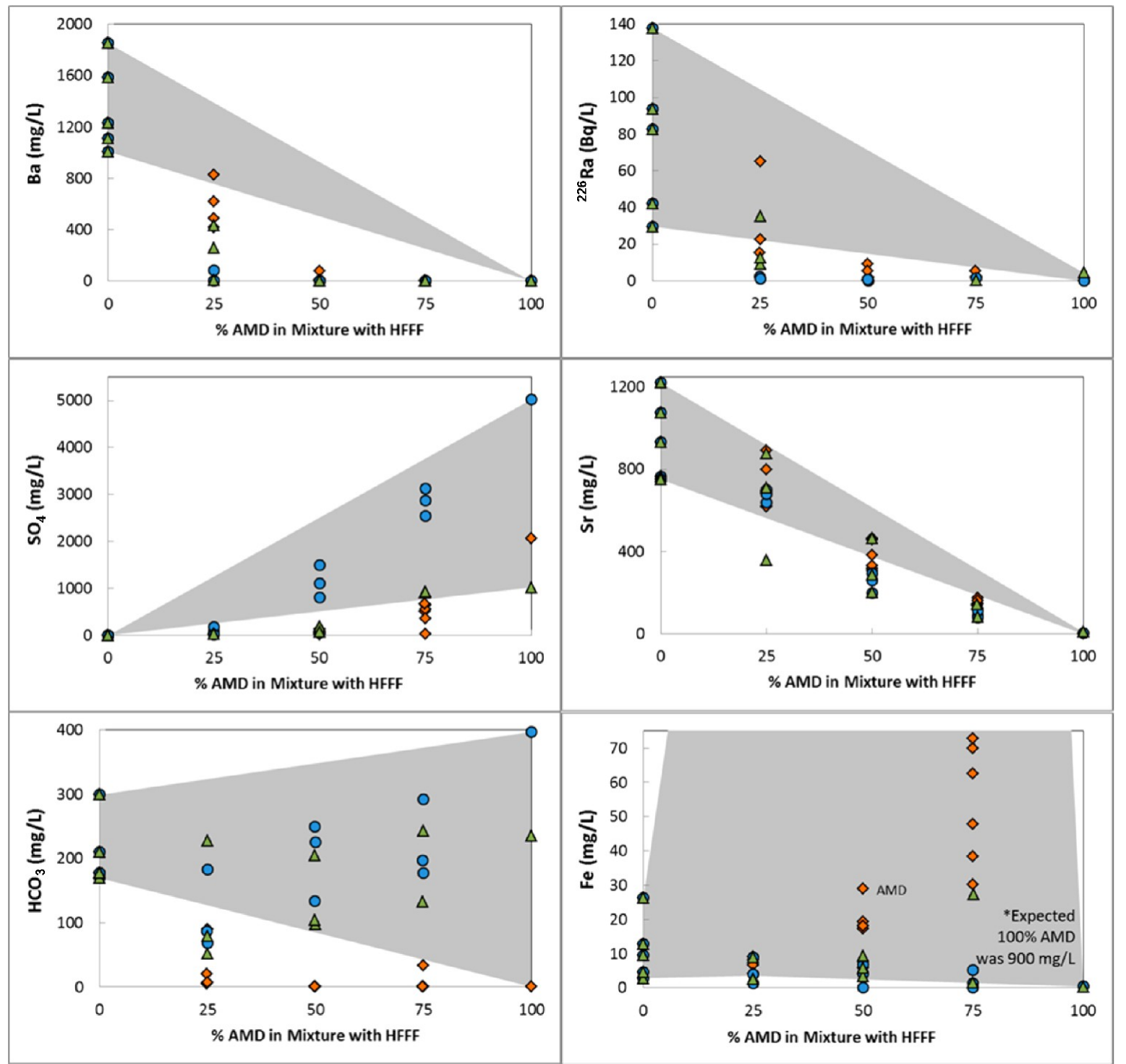

Figure 2. Concentrations of radium, barium, strontium, sulfate, iron, and bicarbonate in different proportions of AMD-HFFF liquid mixtures (expressed as a percentage of AMD in the mixing solution). Areas shaded gray represent expected concentrations with conservative mixing between AMD and HFFF. Actual measured concentrations for each mixture (blue circles, CMD-1; orange diamonds, AMD; and green triangles, CMD-2) that plot within the shaded areas therefore reflect changes in the concentration as a result of mixing. However, for the 50 and $75 \%$ AMD mixtures, the concentrations of radium, barium, strontium, iron, sulfate, and bicarbonate measured in solution were substantially lower than expected from mixing and reflect removal from solution to co-precipitated minerals.

Sample Processing. All major dissolved salts and radioactivity measurements were conducted at Duke University. Major anion concentrations were measured by Dionex IC DX2100 ion chromatography. Major cation concentrations were measured by direct current plasma optical emission spectrometry (DCP-OES). ${ }^{226} \mathrm{Ra}$ activities were determined using a Canberra DSA2000 broad energy germanium $\gamma$ detector at the Laboratory of Environmental RadioNuclides (LEARN). ${ }^{16} \mathrm{~A}$ total of $60 \mathrm{~mL}$ of HFFF, AMD, or mixtures was incubated in sealed cans for at least 3 weeks before measurement through the $609 \mathrm{keV}$ energy line of its decay product, ${ }^{214} \mathrm{Bi}$, assuming a secular equilibrium. The activities of solid samples were calibrated using CCRMP U-Th ore standard DL-la measured under similar physical conditions (e.g., can geometry; see the Supporting Information). Liquid sample efficiency was calibrated to $60 \mathrm{~mL}$ of radium-free seawater spiked with 1 $\mathrm{mL}$ of National Institute of Standards and Technology (NIST)
SRM 4966 standard. Samples were prepared in high-density polyethylene (HDPE) sediment containers with the same geometry and total volume $(60 \mathrm{~mL})$. Background counting measurements were determined by measuring empty containers for $72 \mathrm{~h}$ on three separate occasions. The method detection limit was then conservatively determined by the median values of three $72 \mathrm{~h}$ background measurements of the $609 \mathrm{keV}$ peak area multiplied by three standard deviations. The median background was subtracted from all samples (see Figure S2 of the Supporting Information). X-ray diffraction (XRD) analysis of precipitated solids was performed at Dartmouth College Department of Earth Sciences on Bruker D8 XRD. Solids were dried at $45^{\circ} \mathrm{C}$, crushed with mortar and pestle, and either backpacked or slide-loaded for analysis. Diffraction pattern peak matching was conducted using DIFFRAC ${ }^{\text {plus }}$ BASIC software. 


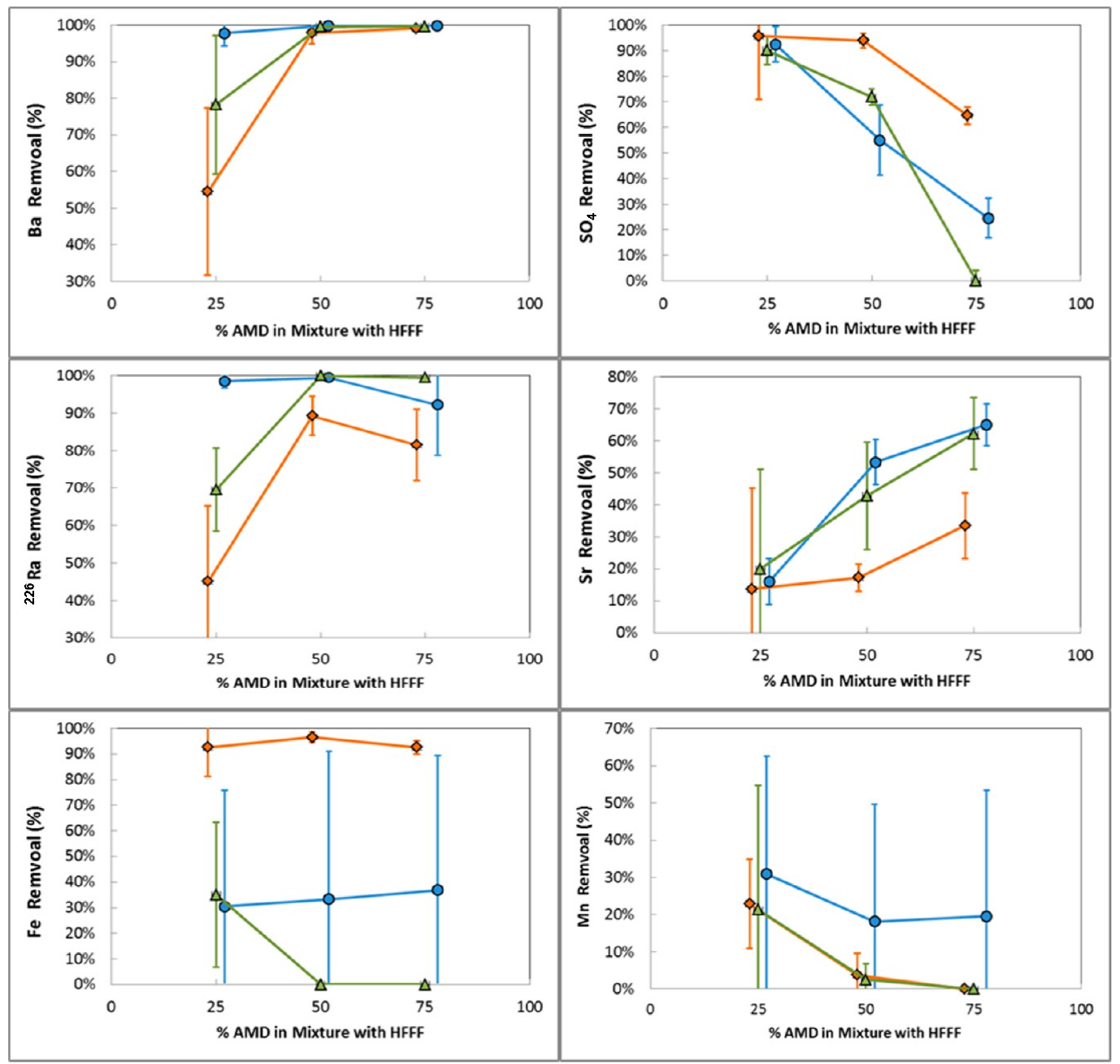

Figure 3. Average removal (in percent) of barium, sulfate, ${ }^{226}$ radium, strontium, iron, and manganese in solutions of different mixed proportions of AMD-HFFF (expressed as a percentage of AMD in the mixed solution). The orange lines represent the low-pH AMD sample; the blue lines represent sample CMD-1; and the green lines represent CMD-2. Note the increase of the removal magnitude of Ra, $\mathrm{Ba}$, and $\mathrm{Sr}$ with the percentage of AMD in the mixing solutions, while sulfate removal showed an opposite trend (and was the limiting factor in the 25\% AMD mixture). Also note the higher removal percentage of $\mathrm{Ra}, \mathrm{Ba}$, and $\mathrm{Sr}$ from high-pH lime-modified AMD (samples CMD-1 and CMD-2) relative to the low-pH AMD. Specific points represent the average values (using three different HFFFs) for each of the three CMD samples, while the error bars represent the variability between the three HFFFs used to create the CMD samples.

\section{RESULTS AND DISCUSSION}

Chemical Characterization of the HFFF, AMD, and Mixing Products. The water samples used for the mixing experiments are representative of AMD and Marcellus HFFF found throughout Pennsylvania. We used two types of AMD: (1) AMD ( $\mathrm{pH}$ 3.4) that was artificially created in the laboratory following Coester et al. ${ }^{22}$ with high concentrations of sodium, iron, and sulfate and low chloride content (sample AMD) and (2) lime-treated AMD with high $\mathrm{pH}(10-11)$, high sodium, sulfate, and chloride, and low iron contents (samples CMD-1 and CMD-2). In contrast, the geochemical characteristics of the HFFF samples were more homogeneous, with elevated chloride, sodium, calcium, strontium, barium, and radium contents, although the absolute concentrations of these elements varied among the three HFFF samples that we used in the experiments (see Table S1 of the Supporting Information).

The mixing of AMD with HFFF caused a reduction in the concentrations of key elements originally present in both the $\operatorname{HFFF}\left(\mathrm{Ba}, \mathrm{Sr}\right.$, and $\left.{ }^{226} \mathrm{Ra}\right)$ and $\mathrm{AMD}\left(\mathrm{SO}_{4}\right.$ and $\mathrm{Fe}$, with $\mathrm{HCO}_{3}$ in the treated AMD) (Figure 2). A conservative (i.e., nonreactive) mixing relationship was observed for the other elements $(\mathrm{Cl}, \mathrm{Na}$, and $\mathrm{Mg}$; see Figure $\mathrm{S} 4$ of the Supporting Information). The resulting removal of sulfate from the aqueous phase was universal for all of the AMD-HFFF mixing combinations, but the magnitude (i.e., percent) of removal decreased with increasing AMD proportions in the mixture (Figure 3). In contrast, Ra, Ba, and Sr removal increased with the increasing fraction of AMD in the mixing solutions (Figure 3). The results suggest that the chemistry (e.g., sulfate) and type of the AMD fluids determine the magnitude and the selective removal of the different ions. The mixing of the modified high-pH AMD (samples CMD-1 and CMD-2) resulted in a larger removal of $\mathrm{Ra}, \mathrm{Ba}$, and $\mathrm{Sr}$ relative to the low-pH, non-treated AMD (sample AMD), yet mixing of the low-pH, Fe-rich AMD resulted in higher removal of iron (Figure 3). Overall, our mixing experiments show a net removal of almost $100 \%$ sulfate (explicitly for low-percent AMD mixing), almost $100 \% \mathrm{Ba}$ and $\mathrm{Ra}$ (for high-percent AMD mixing), up to $70 \% \mathrm{Sr}$ (for high-percent AMD mixing), and up 
Table 1. Mass and Composition of the Precipitants Expected To Form upon the Blending of HFFF and (a) Treated and (b) Untreated AMD at Various Volumetric Ratios Based on Thermodynamic Calculations Using PHREEQC Software ${ }^{a}$

\begin{tabular}{|c|c|c|c|c|c|c|}
\hline (a) $\mathrm{HFFF} /$ treated AMD volume ratio & \multicolumn{2}{|c|}{$50 \% \mathrm{AMD}$ and $50 \% \mathrm{HFFF}$} & \multicolumn{2}{|c|}{$25 \% \mathrm{AMD}$ and $75 \% \mathrm{HFFF}$} & \multicolumn{2}{|c|}{$75 \% \mathrm{AMD}$ and $25 \% \mathrm{HFFF}$} \\
\hline precipitate & M & $\mathrm{mg} / \mathrm{L}$ & M & $\mathrm{mg} / \mathrm{L}$ & M & $\mathrm{mg} / \mathrm{L}$ \\
\hline barite & $4.79 \times 10^{-3}$ & 1176.7 & $7.18 \times 10^{-3}$ & 1675.4 & $2.39 \times 10^{-3}$ & 557.7 \\
\hline calcite & $1.56 \times 10^{-3}$ & 156.0 & $9.08 \times 10^{-4}$ & 90.8 & $2.25 \times 10^{-3}$ & 225.0 \\
\hline celestite & $6.97 \times 10^{-3}$ & 1279.8 & $3.98 \times 10^{-3}$ & 730.8 & $4.13 \times 10^{-3}$ & 758.3 \\
\hline gibssite & $3.15 \times 10^{-6}$ & 0.24 & $4.74 \times 10^{-6}$ & 0.369 & $1.53 \times 10^{-6}$ & 0.119 \\
\hline hematite & $8.15 \times 10^{-5}$ & 7.24 & $4.07 \times 10^{-5}$ & 3.61 & $1.22 \times 10^{-4}$ & 1.08 \\
\hline gypsum & 0 & 0 & 0 & 0 & $5.79 \times 10^{-3}$ & 787.4 \\
\hline total & & 2620 & & 2501 & & 2330 \\
\hline (b) $\mathrm{HFFF} /$ raw AMD volume ratio & $50 \%$ AMD a & HFFF & $25 \% \mathrm{AMD}$ & 6 HFFF & $75 \% \mathrm{AMD}$ & HFFF \\
\hline precipitate & M & $\mathrm{mg} / \mathrm{L}$ & M & $\mathrm{mg} / \mathrm{L}$ & M & $\mathrm{mg} / \mathrm{L}$ \\
\hline barite & $4.79 \times 10^{-3}$ & 1176.7 & $5.38 \times 10^{-3}$ & 1255 & $2.93 \times 10^{-3}$ & 683.8 \\
\hline celestite & $1.71 \times 10^{-3}$ & 313.9 & 0 & 0 & $2.06 \times 10^{-3}$ & 378.3 \\
\hline hematite & $6.89 \times 10^{-5}$ & 32.1 & 0 & 0 & $1.22 \times 10^{-4}$ & 19.4 \\
\hline $\mathrm{SiO}_{2}$ & $2.61 \times 10^{-3}$ & 229.9 & $4.26 \times 10^{-3}$ & 375.6 & $9.58 \times 10^{-4}$ & 84.5 \\
\hline siderite & 0 & 0 & $2.62 \times 10^{-4}$ & 30.3 & 0 & 0 \\
\hline total & & 1753 & & 1661 & & 1166 \\
\hline
\end{tabular}

${ }^{a}$ On the basis of these results, we would expect between 2.3 and $2.6 \mathrm{~g} / \mathrm{L}$ chemical precipitant to form in mixes with treated AMD and between 1.2 and $1.8 \mathrm{~g} / \mathrm{L}$ precipitant in untreated mixes.

to $97 \% \mathrm{Fe}$ (for the AMD sample; Figure 3). These variations suggest that the maximum combined removal of $\mathrm{Ra}, \mathrm{Ba}$, and $\mathrm{Sr}$ will occur upon using lime-treated AMD (samples CMD-1 and CMD-2) relative to untreated and low-pH AMD and that a larger fraction of AMD in the mixture would induce greater removal of these constituents from the aqueous phase (Figure 3).

Solid Precipitants. Geochemical modeling of the saturation state of minerals in the solutions using the PHREEQC software $^{23}$ for each of the different mixing combinations between AMD and HFFF indicates an oversaturation with respect to several minerals (see Figure S1 of the Supporting Information). The saturation index (SI) was derived from PHREEQC ${ }^{23}$ and follows the equation: SI $=\log (\mathrm{IAP} / \mathrm{Ksp})$, where IAP is the ion activity product and Ksp is the apparent equilibrium solubility product. ${ }^{24}$ In particular, we identified the supersaturation state for barite $\left(\mathrm{BaSO}_{4}\right)$ and celestite $\left(\mathrm{SrSO}_{4}\right)$ minerals in the blended waters. The computed saturation states of barite and celestite minerals increased with the percentage of AMD in the mixing solution (see Figure S1 of the Supporting Information) and with sulfate concentrations within the AMD samples (i.e., CMD-1 > AMD > CMD-2; Figure 2). The two types of AMD showed different saturation levels with respect to calcite: higher for the high-pH AMD-blended samples and lower for the low-pH AMD-blended sample. Likewise, blending of the low-pH and Fe-rich AMD sample resulted in a higher saturation level of iron-bearing minerals, such as hematite and siderite (see Figure S1 of the Supporting Information).

The mass of solids expected to precipitate from solution upon mixing treated and untreated AMD and HFFF at three volumetric ratios was calculated using PHREEQC under the assumption that the aqueous and solid phases have reached equilibrium at $25{ }^{\circ} \mathrm{C}$ (Table 1). As opposed to the SI-based evaluation (see Figure $\mathrm{S} 1$ of the Supporting Information), the quantitative precipitation potential (PP) calculates the change in the concentration of each of the relevant solids from the initial mixing state to solid-aqueous equilibrium (Table 1). While SI calculates the theoretical distance from equilibrium of potentially forming solids in the blended solutions, $\mathrm{PP}$ is a measure that takes into account the competition between different solids for a shared dissolved component (e.g., sulfate) and the change in $\mathrm{pH}$ induced by the precipitation and is thus considered a quantitative prediction tool for precipitation of solids from solution. Despite somewhat differing compositions of solids expected to precipitate, the overall mass of solids was roughly constant in all of the scenarios related to mixing treated AMD with HFFF (Table 1). On the basis of PHREEQC calculations, the theoretical precipitated mass amounted to $\sim 2.5 \mathrm{~g} / \mathrm{L}$ treated AMD mixture (using CMD-1). The major precipitants in all three scenarios were barite and celestite, with a small contribution of calcite (and gypsum in the 75\% CMD-1 blend). For blending untreated AMD with HFFF, the software predicts a lower precipitant mass $(\sim 1.3 \mathrm{~g} / \mathrm{L})$ because of the lower sulfate concentrations assumed in this particular AMD stream (2000 versus $5000 \mathrm{mg} / \mathrm{L}$ ). Nevertheless, also in this scenario, the major solid components were composed of barite and celestite, in addition to hematite, which is related to the higher dissolved iron concentration in the untreated AMD. Because of kinetic considerations, we expect that ferrihydrite [amorphous $\mathrm{Fe}(\mathrm{OH})_{3}$ ] would precipitate during the experiments and be transformed to hematite upon aging of the solid.

The solid chemical precipitants for five mixtures of AMD and HFFF were examined using XRD to confirm the presence of the predicted mineral phases. On the basis of the XRD analysis, all five samples appeared to contain strontian barite $\left(\mathrm{Ba}_{0.75} \mathrm{Sr}_{0.25}\right) \mathrm{SO}_{4}$ (see Figure $\mathrm{S} 4$ of the Supporting Information). In one mixture (25\% AMD), quartz was also identified, and in two samples (50\% AMD), halite was also present, although this is thought to be the result of fluid high in $\mathrm{Na}^{+}$and $\mathrm{Cl}^{-}$trapped within the precipitant that subsequently formed halite when dried. The formation of solid strontian barite (or amorphous barite ${ }^{25}$ ) in the precipitant is consistent with the corresponding decrease in dissolved concentrations of barium and strontium in the aqueous phase (Figure 2) as well as the calculated SI and PP values of barite in the mixture. Nonetheless, other mineral phases that were calculated using PHREEQC as oversaturated (see Figure S1 of the Supporting Information), such as siderite, celestite, hematite, and $\mathrm{Fe}(\mathrm{OH})_{3}$, 
were not observed in any of the solid precipitants but could still be present at lower concentrations. Four additional peaks with $d$ spacing of $4.14,3.73-3.68,2.89$, and 2.52 were observed and could represent minor additional phases of $\mathrm{BaCO}_{3}$ or chromite but did not match theoretical phases. Most likely, some of these phases may have precipitated in amorphous form, such as amorphous barite ${ }^{25}$ or ferrihydrite [amorphous $\left.\mathrm{Fe}(\mathrm{OH})_{3}\right]^{26}$ which are indicated by broad XRD peaks (Figure S4).

Precipitation Kinetics. A kinetic experiment was conducted to determine the rate at which the solids precipitate from a representative AMD-HFFF blend. The scenario tested comprised of blending treated AMD (CMD-1) with one of the HFFF samples (FBD) at a 1:1 ratio, while the change in electric conductivity (EC) was continuously monitored during a $35 \mathrm{~h}$ time period (Figure 4). To relate the observed change in

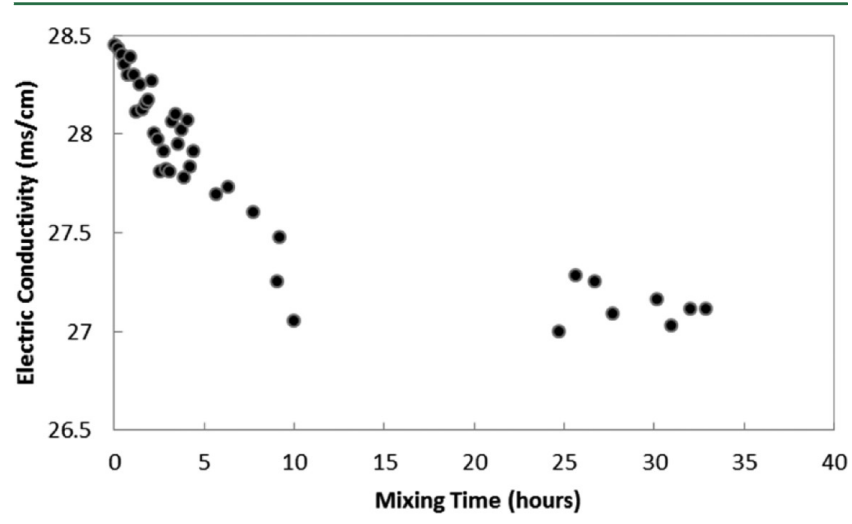

Figure 4. Results of EC variations upon mixture of treated AMD (CMD-1) with HFFF (FBD) at a 1:1 ratio. The change in EC was continuously monitored during a $35 \mathrm{~h}$ time period. The data show that the majority of the precipitation occurred during the first $\sim 10 \mathrm{~h}$ (the EC dropped by $\sim 1.3 \mathrm{mS} / \mathrm{cm}$ ), after which the EC remained constant.

electric conductivity (EC) to total dissolved solids (TDS), an EC-TDS calibration curve was created using $\mathrm{MgSO}_{4}$ salt to represent the divalent ions expected to precipitate and reduce $\mathrm{EC}$ on a background of $\mathrm{NaCl}(33 \mathrm{~g} / \mathrm{L})$ that simulated the blending conditions. The calibration yielded a linear EC-TDS correlation $\left[\mathrm{EC}_{(\mathrm{mS} / \mathrm{cm})}=2000 \mathrm{TDS}_{(\mathrm{mg} / \mathrm{L})}\right]$. The experimental results show that the majority of the precipitation occurred during the first $\sim 10 \mathrm{~h}$, after which the EC did not change further (Figure 4). During the first $10 \mathrm{~h}$, EC dropped by $\sim 1.3$ $\mathrm{mS} / \mathrm{cm}$. On the basis of the EC-TDS calibration equation, this drop corresponds to a change of $2.6 \mathrm{~g}$ of TDS, which is almost identical to the precipitation predicted from this blend by the thermodynamic-based calculation (Table 1).

Radium Co-precipitation. Radium removal for the treated AMD samples (70-100\%) was larger than that of the low-pH AMD mixing (50-80\%; Figure 3). Despite the fact that the CMD-2 sample was characterized by a lower sulfate content $(1000 \mathrm{mg} / \mathrm{L})$ and lower barite and celestite saturation levels (see Figure S1 of the Supporting Information) relative to the AMD sample (2000 mg/L; Figure 2), blending of CMD-2 samples with HFFF resulted in higher radium removal (Figure 3).

Numerous studies have shown that the similarity of the ionic radii of radium and barium, their electronic configuration, and the identical crystallographic structure of pure $\mathrm{RaSO}_{4}$ and $\mathrm{BaSO}_{4}$ (barite) results in co-precipitation of radium with both barite and celestite minerals. ${ }^{27-30}$ Under evaporitic conditions, concurrent removal of radium and barium indicated the precipitation of a $(\mathrm{Ra}, \mathrm{Ba}) \mathrm{SO}_{4}$ solid solution. ${ }^{30}$ The ratio of $\mathrm{Sr} / \mathrm{Ba}$ in the original solution has been shown to affect the $\mathrm{Ra}$ co-precipitation because $\mathrm{Sr}$ appears to be an effective competing ion, causing inhibition of $\mathrm{Ra}$ uptake during formation of the barite-celestite minerals. ${ }^{31}$ Calcite and other carbonate minerals are known to be another possible mechanism for Ra uptake through adsorption to their surface during formation. ${ }^{32}$ Finally, radium can also be removed by coprecipitation to $\mathrm{Mn}$ and $\mathrm{Fe}$ hydrous oxides, ${ }^{33}$ but acidic conditions typically reduce radium retention, ${ }^{34-36}$ particularly for Ra sequestering by iron and manganese oxides. ${ }^{37}$

We propose that radium sequestration during mixing AMD and HFFF is controlled primarily by co-precipitation into $\mathrm{Sr}$ barite mineral. Lime treatment and modification of AMD to alkaline conditions result in a higher magnitude of the overall Ra removal, perhaps because of an additional radium retention/ adsorption on carbonate minerals and/or the high $\mathrm{pH}$ conditions. The differential retention of radium through coprecipitation into barite versus adsorption on carbonate and/or $\mathrm{Mn}$ and Fe hydrous oxides has important environmental health implications with respect to radon emission. It has been shown that the radon emanation fraction from barite scale is 1.5-15fold lower than radon emanation from a typical soil, ${ }^{38}$ thus suggesting less radon emission from radium entrapped in barite relative to adsorbed radium.

Given that we observed almost $100 \%$ radium removal from the aqueous phase, we evaluated the radium level in the solid residues. In this experiment, $250 \mathrm{~mL}$ of $\mathrm{HFFF}$ with $94 \mathrm{~Bq} / \mathrm{L}$ (FBD) was mixed with $250 \mathrm{~mL}$ of radium-free $(<1 \mathrm{~Bq} / \mathrm{L})$ AMD (CMD-1). The residual solids, which included some detrital material (2.494 g), had Ra content of $9405 \mathrm{~Bq} / \mathrm{kg}$. A mass-balance calculation (assuming 100\% Ra retention in solid) resulted in an expected radium content of $9400 \mathrm{~Bq} / \mathrm{kg}$. The nearly identical activity of the theoretical and measured radium concentrations in the solid residues reinforces the validity of the radioactivity measurements in this study and observation of almost $100 \%$ radium retention in the mixed solutions. The level of measured radioactivity exceeds the threshold values of management regulations in the U.S.A. for technologically enhanced naturally occurring radioactive material (TENORM). The threshold values for NORM disposal range from 185 to $1850 \mathrm{~Bq} / \mathrm{kg}$ (5-50 pCi/g; http://www.tenorm.com/regs2. htm). For example, in Michigan, a radiation threshold that would require transportation of solid waste to a licensed radioactive waste disposal facility is $1850 \mathrm{~Bq} / \mathrm{kg}$ (or $50 \mathrm{pCi}$ / $\mathrm{g}$ ). ${ }^{28}$ Thus, in a range of 5-fold (for a standard of $1850 \mathrm{~Bq} / \mathrm{kg}$ ) to 50 -fold (a standard of $185 \mathrm{~Bq} / \mathrm{kg}$ ), dilution with NORM-free solids would be required to allow for disposal of the residual solids waste in a domestic landfill, instead of a licensed radioactive waste disposal facility.

Implications for Mixing AMD and HFFF. Water treatment plants are not always effective at removing all of the radium from flowback and produced waters, which could result in the accumulation of harmful radiation and other toxic levels of chemicals downstream of treatment facilities. ${ }^{1}$ When the HFFF is mixed with AMD, our data show that a large fraction of the radium could be sequestered, leaving residual fluids with $\mathrm{Ra}$ concentrations close to drinking water standards of $0.185 \mathrm{~Bq} / \mathrm{L}$ for combined ${ }^{226} \mathrm{Ra}$ and ${ }^{228} \mathrm{Ra} .{ }^{39}$ The expected high TENORM level in the residual solids would require adequate management using a proper protocol, such as shipment of that waste to a properly licensed landfill ${ }^{40,41}$ and/or blending of those solids with NORM-free solids. ${ }^{42}$ On 
the basis of our measurements, $1 \mathrm{~L}$ of mixed HFFF-AMD wastewater would generate $\sim 2.5 \mathrm{~g}$ of precipitate. Assuming that the 4 million liters of wastewater, which is produced per shale gas well, ${ }^{12}$ will be recycled with AMD and used for further hydraulic fracturing operations, approximately $10000 \mathrm{~kg}$ of residual solids with high NORM are expected to be produced for each shale gas well upon mixing. This means that, for each shale gas well, $50000-500000 \mathrm{~kg}$ or $25-250 \mathrm{~m}^{3}$ (assuming a density of $2 \mathrm{~g} / \mathrm{cm}^{3}$ ) of NORM-free solid waste would be needed to "dilute" the high-NORM solids down to an acceptable NORM range for disposal in a municipal landfill.

For a fluid to be considered usable as HFFF, studies from both Barnett Shale and Marcellus Shale suggested possible water quality ranges for hydraulic fracturing applications, including TDS of $3000-90000 \mathrm{mg} / \mathrm{L}$, calcium up to 350 $\mathrm{mg} / \mathrm{L}, \mathrm{pH}$ between 6.5 and 7.5, iron concentration less than 20 $\mathrm{mg} / \mathrm{L}$, and sulfate concentration less than $1000 \mathrm{mg} / \mathrm{L} .^{15,43} \mathrm{On}$ the basis of these limitations, either the 25 or 50\% AMD blends would be suitable for utilization (Figure 2) for hydraulic fracturing, while the $75 \%$ blend has elevated sulfate levels for one sample (CMD-1) and iron for the low-pH AMD sample (although this can be corrected by adding lime to remove iron).

Our mixing experiments show that significant scale formation is inevitable upon mixing AMD and HFFF $(\sim 2500 \mathrm{~kg} /$ million liter of HFFF). To prevent adverse precipitation of mineral scale within the well bore/formation, mixing of AMD and HFFF prior to the hydraulic fracturing procedure followed by effective solid-aqueous separation, would reduce the scaling potential. The reduction of scaling could be further enhanced by proper addition of scale inhibitors to the AMD-fracturing fluid mixtures. Our kinetic experiment suggests that most of the scaling potential would occur during the first $\sim 10 \mathrm{~h}$, but in the presence of nucleation seeds (i.e., heterogeneous precipitation), the time can be shortened considerably. Future studies should examine whether the co-precipitation of secondary minerals would increase the viscosity of the injected fluids and, thus, increase the gas production or would rather reduce permeability and, thus, gas flows.

Implications for Using Alternative Water Sources for Hydraulic Fracturing. Our laboratory experiments have shown that blending of AMD and HFFF would reduce the sulfate content of the water, making it suitable for hydraulic fracturing operations. Using blends of AMD and recycling shale gas wastewaters for future hydraulic fracturing operations could reduce the environmental impacts induced by disposal of both AMD and HFFF to the environment in areas where AMD sites are located in close proximity to shale gas operations, such as western Pennsylvania (see Figure S5 of the Supporting Information). Future studies should examine other marginal water sources and test their suitability for hydraulic fracturing operations, particularly in areas of high water scarcity, such as Texas ${ }^{8}$ and California. Three types of saline or brackish waters should be considered: (1) waters with predominance of $\mathrm{Ca}$ and $\mathrm{SO}_{4}$ ions (similar to the AMD) with high scaling potential (for example, groundwater from the Ogallala aquifer, southern high plains, Texas, ${ }^{44}$ Trinity and Woodbine aquifers in north-central Texas, ${ }^{45}$ and agricultural return flow in the central valley, California $\left.{ }^{46}\right),(2)$ waters with predominance of $\mathrm{Na}$ and $\mathrm{Cl}$ ions (e.g., southern Gulf Coast aquifer system in Texas ${ }^{47}$ ) with low scaling potential, and (3) hard waters with predominance of $\mathrm{Ca}$, $\mathrm{Mg}$, and alkalinity and high scaling potential of carbonate minerals (e.g., treated domestic wastewater ${ }^{48}$ ). The merit of using marginal waters should be examined for specific cases, but use for hydraulic fracturing could have additional benefits. This approach should also be tested globally because numerous shale gas basins are co-located in areas of high water stress (e.g., the Karoo Basin, South Africa, Tarim and Junggar Basins, northwestern China, and Tindouf Basin, Morocco ${ }^{49}$ ), where fresh water allocation for shale gas development may not be possible.

In conclusion, we show that blending of AMD with HFFF results in precipitation of secondary minerals (e.g., Sr barite and iron-bearing minerals) and sequestration of toxic levels of radium, barium, and strontium. The mixing experiments revealed the optimal conditions in which the NORMs and toxic metals can be removed, controlled by both the $\mathrm{pH}$ and sulfate concentration of the solution. The optimization of the NORM sequestration resulted in NORM-free solution but with high NORM levels in residual solids that need to be adequately managed and disposed. While the laboratory tests have shown that it is technically possible to generate water effluents suitable for hydraulic fracturing, field-scale tests are necessary to confirm this feasibility under operational conditions.

\section{ASSOCIATED CONTENT}

\section{Supporting Information}

Additional details on the analytical method of radium measurement, the chemical composition of the AMD and HFFF samples, the chemical composition of the different mixing samples, and saturation indices. This material is available free of charge via the Internet at http://pubs.acs.org.

\section{AUTHOR INFORMATION}

\section{Corresponding Author}

*Telephone: 919-681-8050. Fax: 919-684-5833. E-mail: vengosh@duke.edu.

\section{Present Address}

${ }^{\S}$ Department of Earth Sciences, Dartmouth College, Hanover, NH 03755, United States.

\section{Notes}

The authors declare no competing financial interest.

\section{ACKNOWLEDGMENTS}

Treated AMD and HFFF were provided by Consol Energy, Inc. We thank Gary Dwyer, Alissa White, and Ellie Kern for providing invaluable guidance and sample analyses throughout the project and Tim Johnson for advising. Joshua Landis and Edward Meyer of Dartmouth College provided valuable training and discussion of XRD results. Loren Anderson of the Marcellus Shale Coalition helped by providing his guidance, networking, and project development expertise. Nathaniel Warner was supported by the National Science Foundation (NSF) Partnerships for International Research and Education (PIRE) award (NSF-OISE-12-43433). We thank the editor and four anonymous reviewers for valuable and critical comments that improved the quality of this manuscript.

\section{REFERENCES}

(1) Warner, N. R.; Christie, C. A.; Jackson, R. B.; Vengosh, A. Impacts of shale gas wastewater disposal on water quality. Environ. Sci. Technol. 2013, 47 (20), 11849-11857.

(2) Vengosh, A.; Warner, N. R.; Jackson, R. B.; Darrah, T. The effects of shale gas exploration and hydraulic fractruing on the quality of water resources in the United States. Procedia Earth Planet. Sci. 2013, 7, 863-866. 
(3) Barbot, E.; Vidic, N. S.; Gregory, K. B.; Vidic, R. D. Spatial and temporal correlation of water quality parameters of produced waters from Devonian-age shale following hydraulic fracturing. Environ. Sci. Technol. 2013, 47 (6), 2562-2569.

(4) Rowan, E. L.; Engle, M. A.; Kirby, C. S.; Kraemer, T. F. Radium Content of Oil- and Gas-Field Produced Waters in the Northern Appalachian Basin (USA)-Summary and Discussion of Data: U.S. Geological Survey Scientific Investigations Report 2011-5135; United States Geological Survey (USGS): Reston, VA, 2011.

(5) Kargbo, D. M.; Wilhelm, R. G.; Campbell, D. J. Natural gas plays in the Marcellus Shale: Challenges and potential opportunities. Environ. Sci. Technol. 2010, 44 (15), 5679-5684.

(6) Kappel, W. M. Water Resources and Shale Gas/Oil Production in the Appalachian Basin-Critical Issues and Evolving Developments; United States Geological Survey (USGS): Reston, VA, 2013.

(7) Ferrar, K. J.; Michanowicz, D. R.; Christen, C. L.; Mulcahy, N.; Malone, S. L.; Sharma, R. K. Assessments of effluent contaminants from three wastewater treatment plants discharging Marcellus Shale wastewater to surface waters in Pennsylvania. Environ. Sci. Technol. 2013, 47 (7), 3472-3481.

(8) Nicot, J. P.; Scanlon, B. R. Water use for shale-gas production in Texas, U.S. Environ. Sci. Technol. 2012, 46 (6), 3580-3586.

(9) Murray, K. E. State-scale perspective on water use and production associated with oil and gas operations, Oklahoma, U.S. Environ. Sci. Technol. 2013, 47 (9), 4918-4925.

(10) Jackson, R. E.; Gorody, A. W.; Mayer, B.; Roy, J. W.; Ryan, M. C.; Van Stempvoort, D. R. Groundwater protection and unconventional gas extraction: The critical need for field-based hydrogeological research. Groundwater 2013, 51 (4), 488-510.

(11) Johnson, E. G.; Johnson, L. A. Hydraulic fracture water usage in northeast British Columbia: Locations, volumes, and trends. Geoscience Reports; British Columbia Ministry of Energy and Mines: Victoria, British Columbia, Canada, 2012; pp 41-63.

(12) Lutz, B. D.; Lewis, A. N.; Doyle, M. W. Generation, transport, and disposal of wastewater associated with Marcellus Shale gas development. Water Resour. Res. 2013, 49 (2), 647-656.

(13) Maloney, K. O.; Yoxtheimer, D. A. Production and disposal of waste materials from gas and oil extraction from the Marcellus Shale play in Pennsylvania. Environ. Pract. 2012, 14 (4), 278-287.

(14) McSurdy, S. Utilizing Acid Mine Drainage for Marcellus Shale Activities in Pennsylvania; National Energy Technology Laboratory (NETL): Pittsburgh, PA, 2011.

(15) Curtright, A. E.; Giglio, K. Coal mine drainage for Marcellus Shale natural gas extraction. Proceedings and Recommendations from a Roundtable on Feasibility and Challenges; Rand Corporation: Pittsburgh, PA, 2012; p 47.

(16) Reinhardt, C. H. Acid mine drainage in Pennsylvania streams: "Ironing out" the problem. Restor. Reclam. Rev. 1999, 5 (1), 1-10.

(17) Ziemkiewicz, P. F.; Skousen, J. G.; Simmons, J. E. Long-term performance of passive acid mine drainage treatment systems. Mine Water Environ. 2003, 22 (3), 118-129.

(18) ProChemTech International, Inc. Treatment of Abandoned Mine Drainage for Use as Marcellus Gas Well Hydrofracture Makeup Water; ProChemTech International, Inc.: Brockway, PA; http://www. prochemtech.com/Literature/TAB/PDF_TAB_Marcellus Hydrofracture Water Supply \%20From AMD 1009.pdf.

(19) He, C.; Z Zhang, T.; Vidic, R. D. Use of abandoned mine drainage for the development of unconventional gas resources. Disruptive Sci. Technol. 2013, 1 (4), 169-176.

(20) Ziemkiewicz, P. F.; Skousen, J. G.; Brant, D. L.; Sterner, P. L.; Lovette, R. J. Acid mine drainage treatment with armored limestone in open limestone channels. J. Environ. Qual. 1997, 26 (4), 1017-1024.

(21) Wang, X. Use of acid mine drainage in recycling of Marcellus Shale flowback water: Solids removal and potential fouling of polymeric microfiltration membranes. Master's Thesis, University of Pittsburgh, Pittsburgh, PA, 2012.

(22) Coetser, S. E.; Pulles, W.; Heath, R. G. M.; Cloete, T. E. Chemical characterization of organic electron donors for sulfate reduction for potential use in acid mine drainage treatment. Biodegradation 2006, 17, 67-77.

(23) Parkhurst, D. L.; Appelo, C. A. Description of input and examples for PHREEQC version 3-A computer program for speiation, batch-reaction, one-dimensional transport, and inverse geochemical calculations. U.S. Geological Survey Techniques and Methods; United States Geological Survey (USGS): Reston, VA, 2013; Book 6, Chapter A43, p 497.

(24) Jones, F. Infrared investigation of barite and gypsum crystallization: Evidence for an amorphous to crystalline transition. CrystEngComm 2012, 14, 8374-8381.

(25) Jones, F. Infrared investigation of barite and gypsum crystallization: Evidence for an amorphous to crystalline transition. CrystEngComm 2012, 14, 8374-8381.

(26) Ames, L. L.; McGarrah, J. E.; Walker, B. A.; Salter, P. F. Uranium and radium sorption on amorphous ferric oxyhydroxide. Chem. Geol. 1983, 40, 135-148.

(27) Langmuir, D.; Riese, A. C. The thermodynamic properties of radium. Geochim. Cosmochim. Acta 1985, 49, 1593-1601.

(28) Lanmuir, D.; Melchior, D. The geochemistry of Ca, Sr, Ba and $\mathrm{Ra}$ sulfates in some deep brines from the Palo Duro Basin, Texas. Geochim. Cosmochim. Acta 1985, 49 (11), 2423-2432.

(29) Gordon, L.; Rowley, K. Coprecipitation of radium with barium sulfate. Anal. Chem. 1957, 29 (1), 34-37.

(30) Rosenberg, Y. O.; Metz, V.; Ganor, J. Radium removal in a large scale evaporitic system. Geochim. Cosmochim. Acta 2013, 103, 121137.

(31) Ceccarello, S.; Black, S.; Read, D.; Weiss, H.; Schubert, M.; Kunze, C.; Grossmann, J. Radioactive scales from a natural gas production facility in the Altmark region, Germany. Proceedings of the 8th International Congress on Applied Mineralogy (ICAM2004); Aguas de Lindoia, São Paulo, Brazil, Sept 19-22, 2004; pp 395-398.

(32) Jones, M. J.; Butchins, L. J.; Charnock, J. M.; Pattrick, R. A.; Small, J. S.; Vaughn, D. J.; Wincott, P. L.; Livens, F. R. Reactions of radium and barium with the surfaces of carbonate minerals. Appl. Geochem. 2011, 26, 1231-1238.

(33) Kronfeld, J.; Ilani, S.; Strull, A. Radium precipitation and Useries disequilibrium along the Dead Sea coast. Appl. Geochem. 1991, $6 p, 355-361$.

(34) Dickson, B. L.; Herzceg, A. L. Deposition of trace elements and raionuclides in the spring zone, Lake Tyrrell, Victoria, Australia. Chem. Geol. 1992, 79, 151-166.

(35) Cecil, L. D.; Smith, R. C.; Reilly, M. A.; Rose, A. W. Radon, radium and other radioactivity in ground water: Hydrogeologic impact and appliction to indoor airborne contamination. Proceedings of the National Water Well Association (NWWA) Conference; Somerset, NJ, April 7-9, 1987; pp 437-447.

(36) Bolton, D. W.; Grace, J. W.; Hansen, H. J. Radium in low-pH, high-dissolved-solids ground water in the Maryland coastal plain. Proceedings of the Virginia Water Research Symposium; Roanoke, VA, Nov 7-9, 2000.

(37) Al-Hobaib, A. S.; Al-Sulaiman, K. M.; Al-Dhayan, D. M.; AlSuhybani, A. A. Removal of radium from sand filters by inorganic acids. J. Radioanal. Nucl. Chem. 2006, 268, 425-431.

(38) Rood, A. S.; White, G. J.; Kendrick, D. T. Measurement of $222 \mathrm{Rn}$ flux, 222Rn emanation, and 226,228Ra concentration from injection well pipe scale. Health Phys. 1998, 75 (2), 187-192.

(39) United States Environmental Protection Agency (U.S. EPA). National Primary Drinking Water Regultions; U.S. EPA: Washington, D.C., 2012

(40) Lustgarten, A. Is New York's Marcellus Shale Too Hot to Handle; ProPublica: New York, 2009.

(41) PSE Report: Research Needed to Address Signs of Health, Environmental Dangers of Fracking. Manufacturing Close-Up, 2012.

(42) Smith, K. P.; Arnish, J. J.; Williams, G. P.; Blunt, D. L. Assessment of the disposal of radioactive petroleum industry waste in nonhazardous landfills using risk-based modeling. Environ. Sci. Technol. 2003, 37 (10), 2060-2066. 
(43) Hayes, T. Proceedings and Minutes of the Hydraulic Fracturing Expert Panel; XTO Facilities, Fort Worth, TX, Sept 26, 2007.

(44) Mehta, S.; Fryar, A. E.; Banner, J. L. Controls on the regionalscale salinization of the Ogallala aquifer, southern high plains, Texas, USA. Appl. Geochem. 2000, 15, 849-864.

(45) Chaudhuri, S.; Ale, S. Characterization of groundwater resources in the Trinity and Woodbine aquifers in Texas. Sci. Total Environ. 2013, 452-453, 333-348.

(46) Kharaka, Y. K.; Ambats, G.; Presser, T. S.; Davis, R. A. Removal of selenium from contaminated agricultural drainage water by nanofiltration membranes. Appl. Geochem. 1996, 11, 797-802.

(47) Gates, J. B.; Nicot, J. P.; Scanlon, B. R; Reedy, R. C. Arsenic enrichment in unconfined sections of the southern Gulf Coast aquifer system, Texas. Appl. Geochem. 2011, 26, 421-431.

(48) Vengosh, A. Environmental geochemistry. In Treatise in Geochemistry, 2nd ed.; Sherwood Lollar, B., Ed.; Elsevier Science: Amsterdam, Netherlands, 2013; Vol. 11, pp 325-378.

(49) U.S. Energy Information Administration (EIA). Technically Recoverable Shale Oil and Shale Gas Resources: An Assessment of 137 Shale Formations in 41 Countries Outside the United States; EIA: Washington, D.C., 2013.

(50) Carnegie Museum of Natural History. Carnegie Museum of Natural History Pennsylvania Unconventional Natural Gas Wells Geodatabase; Carnegie Museum of Natural History: Pittsburgh, PA, 2000-2013. 